\title{
RETRACTION
}

W) Check for updates

Cite this: J. Mater. Chem. A, 2017, 5 , 24016

DOI: $10.1039 / \mathrm{c} 7 \operatorname{ta} 90259 j$

www.rsc.org/MaterialsA

\section{Retraction: Chemical etching of a cobalt-based metal-organic framework for enhancing the electrocatalytic oxygen evolution reaction}

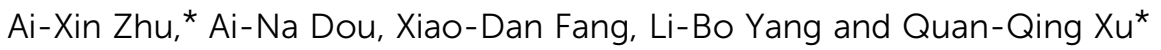 \\ Retraction of 'Chemical etching of a cobalt-based metal-organic framework for enhancing the electrocatalytic \\ oxygen evolution reaction' by Ai-Xin Zhu et al., J. Mater. Chem. A, 2017, DOI: 10.1039/c7ta02103h.
}

We, the named authors, hereby wholly retract this Journal of Materials Chemistry A article.

After first publication of this article we became aware that the crystal structure data, SEM images and TEM images, namely Fig. 1 and S6, do not correspond to the samples of the MOF that we synthesised in the experiments reported in this paper.

We do not have the facilities to repeat these characterisation methods in our laboratory to verify the characteristics of the reported MOF and therefore we are retracting this paper to protect the accuracy and integrity of the scientific record.

Signed: Ai-Xin Zhu, Ai-Na Dou, Xiao-Dan Fang, Li-Bo Yang and Quan-Qing Xu.

$23^{\text {rd }}$ October 2017.

Retraction endorsed by Annie Harvey, Executive Editor, Journal of Materials Chemistry A. 